\title{
Interlanguage and its Implications in L2 Teaching ${ }^{1}$
}

\author{
Liu Qingxue \\ presently visiting Institute of Linguistics, Adam Mickiewicz University \\ ul. Międzychodzka 5, 60-371 Poznań, POLAND
}

liugx1952@yahoo.com.cn

\begin{abstract}
Recent research has shown that adult students learning a second or foreign language generally form a systematic interlanguage grammar which is influenced by both the mother tongue and the target language and has features of each. This interlanguage continues to approximate and improve in the process of the learner's second language acquisition towards the final internalization of the target language system. In this paper, the author introduces the Interlanuage Hypothesis, analyses its nature and mainly based on the cases of the Chinese adult learners of English, explores the specific characteristics of the interlanguage grammar - its phonology, morphology, syntax and semantics. Towards the end of the paper the author also points out some implications the lnterlanguage research might have on the practical fields of our contemporary second language teaching and learning.
\end{abstract}

\section{Introduction}

In the case of first language (L1) acquisition, we may ascribe the difference between child and adult grammars to either cognitive or biological immaturity in the child. In the case of second language (L2) learning by adults, however, we cannot say that the learners are either cognitively or biologically immature. Recent research has shown that L2 learners have a systematic interlanguage (IL) grammar - so called because it is influenced by both L1 and L2 and has features of each (Archibald, J. 1997). The following diagram shows the situation:

$$
\text { L1 } \rightarrow \text { interlanguage } \leftarrow \text { L2 }
$$

Figure 1 Influences on an interlanguage

\footnotetext{
1 The author is grateful to Dr. Maciej Karpinski, Institute of Linguistics, Adam Mickiewicz University, Poznań, for his useful suggestions and helpful guidance. For any weaknesses and inconsistencies which may still remain, the author himself is responsible.
} 
The interlanguage hypothesis was first proposed by the American psycholinguist Larry Selinker in 1972, who explained the well known fact that L2 learners' utterances in the target language (TL) differed from those produced by native speakers to express the same thing, and then postulated the existence of a separate linguistic system for L2 learners. The term "interlanguage" suggests that the learner's language will show the features of both $\mathrm{L} 1$ and TL. In other words, interlanguage is a transitional system used by L2 learners and it has a structurally intermediate status between the two codes - the native and the target language. Nemser, an American linguist, called it approximative system to suggest that interlanguage develops towards the TL system, gradually approaching it. Pit Corder, a famous British linguist, used the term transitional competence to suggest that the learner possesses some knowledge of the language which he constantly develops (Sobolew, L. 1986).

\section{The Nature of an Interlanguage}

Interlanguage can be described as a system which is dynamic, variable and often fossilized, and whose structure is simple and function reduced.

\subsection{Being Dynamic, Variable and Fossilized}

We can call interlanguage dynamic because it undergoes constant change in the process of learning. Interlanguage shows variability because learners vary in their individual performance over time. And when the interlanguage stops changing, it is said to have fossilized.

According to the Ontogency Model of second language acquisition (SLA) (Major, R. 1987), there are two types of errors in an IL grammar: transfer error and developmental error. The former type of error reflects transfer from L1. In contrast, the latter depends on the level of proficiency of L2 learners. Beginning learners may have nothing to draw on but their L1. More advanced learners, however, have acquired a certain amount of knowledge about L2 and this knowledge becomes a potential source of error. This is illustrated in Figure 2 (Archibald, J. 1997):

\begin{tabular}{|c|c|c|}
\hline Level of proficiency & Transfer errors & Developmental errors \\
\hline Beginner & high & low \\
\hline Intermediate & medium & high \\
\hline Advanced & low & low \\
\hline
\end{tabular}

Figure 2. Error patterns in L2 learners

The Ontogeny Model also predicts that the number of transfer errors should decrease over time, whereas the number of developmental errors should be small initially but then should increase before finally decreasing, as is shown in Figure 3 (Archibald, J. 1997):
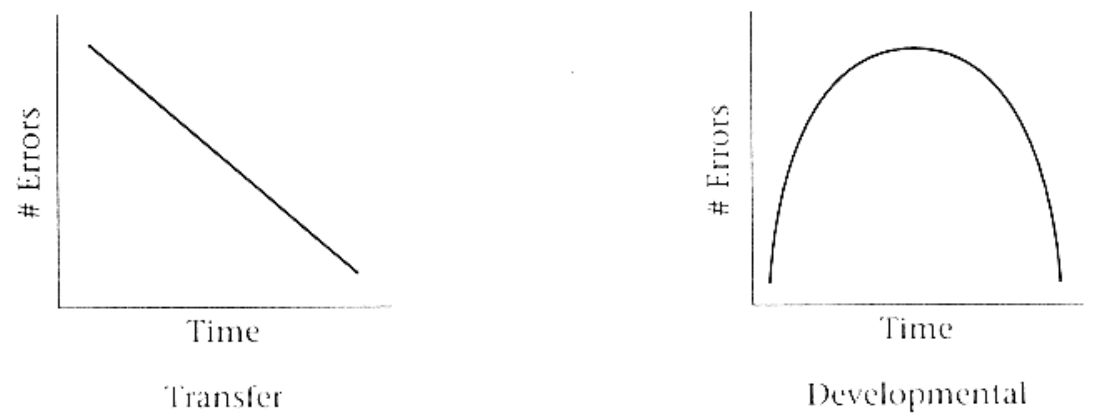

Figure 3. Error patterns predicted by the Ontogeny Model 
So we can see that the IL grammar is influenced by both L1 and L2, though the proportion of influence is dependent on the learner's level of overall proficiency. And we may also have noticed that advanced learners have low numbers of both transfer and developmental errors. However, not all learners can reach the advanced stage. Some learners will continue to elaborate their TL only so long as they have a sufficient motivation for doing so. When they have found that they can communicate well enough for their normal purposes with native speakers, they cease to learn. We all know foreigners in our community whose language has fossilized, who continue to make the same errors even if they have been exposed to TL for a very long time (Corder, 1973, 1981).

\subsection{Being Structurally Simple}

Interlanguage is also viewed as a structurally simple system. It has been observed that interlanguages of L2 learners share important features with other simple systems of codes, such as baby talk (greatly simplified type of speech like that used by adults addressing young children or other adults in intimate situations), foreigner talk (rather distinctive style of speech people use in talking to a foreigner who does not speak the TL very well), and pidgins (a crude and clumsy system of communication, with no recognizable grammar, stitched together out of bits and pieces of one or more natural languages and used by people who have no language in common), especially at the early stages of L 2 development.

Such codes as baby talk, foreigner talk and pidgins are usually characterized by reduced redundancy (the property of language by which an utterance typically contains more information than is strictly necessary to understand it, but this property is crucial since its presence means we can often understand an utterance even if we fail to hear bits of it), increased regularity (such as more fixed word order), reduced vocabulary and less stylistic variation. For example, interlanguage learners usually drop redundant features like articles, while in pidgin among most obvious features are: a very simple or nonexistent morphological system, unmarked gender, and no conjunction. Foreigner talk is characterized by fixed word order, no articles, drastically reduced prepositions, special way of expressing negation as "You no come", etc. (Sobolew, L. 1986)

\subsection{Being Functionally Reduced}

Interlanguage is also reduced functionally, that is, L2 learners cannot use their interlanguage for all communicative purposes as well as they use their native language. So the IT speakers are likely to resort to risk-avoiding strategies in communication with the native speakers: avoid certain topics, say less than intended by means of topic avoidance, semantic avoidance (not saying what they want to say but what they can say!), and content reduction (using more general vocabulary) or even refuse further interaction.

\section{Interlanguage Grammars}

The L2 learner's performance is said to result from his IT system or grammar. And it appears that the mother tongue can be blamed for a certain proportion of errors, such as imposing L1 phonology, morphology, syntax and semantics upon the learner's performance in the TL. Then what is the structure or grammar of an Interlanguage? And what are the features of the phonology, morphology, syntax and semantics of the L2 learners? Let us examine what the Chinese adult learners acquire in the domains mentioned above when learning English as a foreign language(FL).

\subsection{L2 Phonology}

Languages vary in terms of sound production, especially English and Chinese, the former belongs to the Indo-European language family, whereas the latter falls into the Sino-Tibetan family. The two languages being so different, Chinese adult learners of English tend to pronounce words using 
their L1 phonological system, particularly at a beginning level of proficiency. Figure 4 illustrates some typical pronunciation errors made by the Chinese speakers.

\begin{tabular}{|c|c|c|}
\hline English Target & Wrong Sound & Comment \\
\hline [e] in red & [red] & \multirow{3}{*}{$\begin{array}{l}\text { There are no exact equivalent sounds for [e], [æ] and [ai] } \\
\text { in Chinese pronunciation. Many learners can not } \\
\text { differentiate the } 3 \text { sounds and tend to choose the sound }[\varepsilon] \\
\text { in between. }\end{array}$} \\
\hline [æ] in hat & [het] & \\
\hline [ai] in smile & [smel] & \\
\hline [a:] in laugh & [laf] & $\begin{array}{c}\text { In Chinese the sound [a:] is not pronounced long enough, } \\
\text { with the mouth not opening wide enough. }\end{array}$ \\
\hline [0:] in short & {$\left[\int \mathrm{ot}\right]$} & $\begin{array}{c}\text { The sound [0:] is not pronounced long enough, with the } \\
\text { mouth opening wider. }\end{array}$ \\
\hline [au] in out & {$[\mathrm{ot}]$} & $\begin{array}{l}\text { The sound [au] is often pronounced shorter, with the } \\
\text { mouth not opening wide enough. }\end{array}$ \\
\hline [əu] in Polish & ['polif] & The sound [əu] is often pronounced something like [o]. \\
\hline 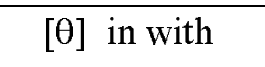 & [wis] & \multirow{2}{*}{$\begin{array}{l}{[\theta] \text { and }[ð] \text { do not exist in the Chinese sound system. So }} \\
\text { learners tend to use }[\mathrm{s}] \text { and }[\mathrm{z}] \text { as substitutes. }\end{array}$} \\
\hline [ð] in that & [zet] & \\
\hline [v] in very & ['weri] & $\begin{array}{l}\text { In Chinese [v] does not exist. Learners are apt to } \\
\text { pronounce }[\mathrm{w}] \text { instead. }\end{array}$ \\
\hline [n] in nod & [lod] & $\begin{array}{l}\text { The southerners in China tend to pronounce [1] instead of } \\
\text { the nasal sound [n]. }\end{array}$ \\
\hline
\end{tabular}

Figure 4. Some pronunciation errors found in Chinese adult learners of English

\subsection{L2 Morphology}

L2 morphology has been studied more or less in a theoretical vacuum (Archibald, J. 1997). In the 1970 s, a number of studies collected data on the accuracy of L2 learners on a variety of morphemes. This research drew on the previous studies of first language acquisition (FLA) that had attempted to determine the order of acquisition of morphemes in Ll development. The following development sequence was found.

In Figure 5 and Figure 6, we may have noticed that there are many similarities but there are also some differences. For instance, auxiliary and copula be are acquired at a relatively earlier point of time in L2 than in L1, and the possessive morpheme - 's is acquired later in L2 than in L1. Whether the result of this research is true of Chinese adult learners of English is worth further investigating. But it may shed some light on the level of difficulties of Chinese adults in learning the English morphemes.

\begin{tabular}{|c|l|l|}
\hline Serial No. & Morpheme & Example \\
\hline 1 & - ing & He is working. \\
\hline
\end{tabular}




\begin{tabular}{|l|l|l|}
\hline 2 & Plural $-s$ & books \\
\hline 3 & Irregular past & She taught German. \\
\hline 4 & Possessive $-s$ & child' $s$ toy \\
\hline 5 & Copula $b e$ & I am happy. \\
\hline 6 & Articles & $a$, the \\
\hline 7 & Regular past & She walked quickly. \\
\hline 8 & Third person $-s$ & He speaks fast. \\
\hline 9 & Auxiliary $b e$ & She is singing. \\
\hline
\end{tabular}

Figure 5. Developmental order for FLA of morphemes

Research on second language acquisition (SLA) focused on whether the developmental sequence in L2 learning was the same for L1 learning. The following order was found.

\begin{tabular}{|c|l|}
\hline Serial No. & Morpheme \\
\hline 1 & -ing \\
\hline 2 & Copula $b e$ \\
\hline 3 & Articles \\
\hline 4 & Auxiliary $b e$ \\
\hline 5 & Plural $-s$ \\
\hline 6 & Irregular past \\
\hline 7 & Regular past \\
\hline 8 & Third person $-s$ \\
\hline 9 & Possessive $-s$ \\
\hline
\end{tabular}

Figure 6. Developmental order for SLA of morphemes

\subsection{L2 Syntax}

L2 learners also have to acquire the syntax of their interlanguage. Thus, as a result of the interference of the mother tongue, Chinese adult learners tend to use their L1 grammatical knowledge in forming English sentences:

*I very happy.

*He is student.

In the Chinese language, if we say “我很高兴” wo hen gaoxin (The literal translation is "I very happy."), it is perfect. There is no syntactic problem in the sentence structure. But in English, we have to say “I am happy." Likewise, “他是学生” ta shi xuesheng (The literal translation is "He is student."), is a syntactically correct sentence, because there is no article in the Chinese language. However, we must use an indefinite article before the noun in the English sentence: "He is $a$ student."

Errors made due to the interference of the mother tongue are often called interlingual or transfer errors. In fact, many syntactic errors made by Chinese L2 learners can also be observed 
in the speech of learners from other countries, even in the utterances of those with native language background, especially in their early childhood. The following utterances may serve as examples of syntactic overgeneralization:

*This is more good.

*What did you wanted to buy?

*Do you can cook well?

Such errors are called developmental or intralingual errors. Jack Richards, one of the leading American linguists, offers the following explanation: "Intralingual errors are those which reflect the general characteristics of rule learning, such as faulty generalization, incomplete application of rules and failure to learn conditions under which rules apply. Developmental errors illustrate the learner attempting to build hypotheses about the TL from his limited experience of it." (Richards, 1973)

So the syntax of L2 learners' interlanguage may produce two kinds of errors: interlingual and intralingual. Making distinctions between the two may help L2 teachers to deal with the IT syntactic problems better.

\subsection{L2 Semantics}

L2 learners may also make semantic errors in their effort to acquire the semantics of their IT grammar. Now look at the following utterances:

1) *I have accepted the invitation to her birthday party, but I don't want to receive it.

2) *Tomorrow I will go to the Swedish embassy in Warsaw and I will send the documents for visa application to the immigration officer there.

In Utterance 1), the speaker mixed up the meaning of the two words "accept" (meaning “接受” jieshou in Chinese) and "receive" (meaning “收到" shoudao in Chinese), presumably because each of the Chinese translation has the sound shou in it. Thus the utterance sounds contradictory to the hearer: How can it be that you have accepted her invitation, but you do not want to receive it? It will sound natural if the two verbs exchange places, with some necessary changes in form, of course.

Utterance 2) may make the addressee most perplexed: Since you are going to the embassy yourself tomorrow, then why do you have to mail the documents instead of bringing them with you and presenting them to the immigration officer there by yourself? In fact the problem lies in the speaker's wrong assumption about the meaning and usage of the verb "send", which in Chinese can be translated into “送” song. We can say “送信” songxin (send a letter), “送人” songren (see somebody off), “送文件” songwenjian (submit documents), etc. So the speaker is most probably to have assumed that the Chinese character "送" is equivalent to the English word "send" and it can be used in all the phrases and contexts mentioned above .

\section{Implications for L2 Teaching}

Based on error analysis which studies the learner's errors and tries to get evidence of how language is learnt or acquired and what strategies or procedures the learner is employing in his discovery of the language (Corder 1981), the interlanguage hypothesis is an important development of research into the nature of SLA. Though the IT hypothesis is not perfect and still more research is needed, it has aroused attention of both theoretical and applied linguists. Its implications in L2 teaching and learning are obvious. For instance, being aware that interlanguage forms an inseparable part of the process of $\mathrm{L} 2$ learning, the teacher is apt to

1) adopt a realistic and positive attitude towards the learner's errors, accept errors as a strategy of learning and correct them selectively,

2) encourage communication in the classroom, promote risk-taking strategies in the learner - even at the cost of making errors, 
3) relax control over the linguistic forms the learner is exposed to and balance activities that focus on accuracy and fluency,

4) make predictions about the possible interference of $\mathrm{L} 1$ on $\mathrm{TL}$, and try to help the learner to decrease transfer/interlingual errors,

5) choose or compile teaching materials or textbooks suitable to the learner's level of proficiency, improve the learner's strategies of learning and try to minimize intralingual/developmental errors through systematic instruction.

Realizing the existence of an unavoidable IT grammar, a L2 learner is likely to

1) overcome his anxieties in SLA, and make a practical plan of approximating TL,

2) pay special attention to the teacher's instruction about $\mathrm{L} 1$ interference on $T L$, and try to make less transfer or interlingual errors,

3) work out strategies of experimentation with the target language, try to develop the new language into an ordered system, and revise this system progressively,

4) cultivate an effective personal learning style or positive learning strategy, and try to decrease developmental or intralingual errors,

5) use risk-taking communication strategies - even at the cost of making errors, and be willing to use the language both in the classroom and real communication.

As the study of interlanguage develops and we gain more insight into the complex problems of second language learning, its relevance to language teaching will be further increased.

\section{Conclusion}

Second language learning is basically a creative process of rule discovery and hypothesis testing by means of various cognitive activities on the part of the learner. This process is strongly influenced by $\mathrm{L} 1$ and TL, thus creating a new language system - called interlanguage. According to the interlanguage hypothesis, a second language learner has at any given point of time in the acquisition process an interim-stage or interlanguage grammar. This grammar changes in response to incoming data, so that with continued exposure to sufficient and appropriate input, the interlanguage grammar, by a series of successive approximations, moves closer and closer to the standard grammar of the target language (Kilborn, K. 1994).

The IT hypothesis has been and continues to be influential in both theoretical and applied linguistic fields. Being aware of the hypothesis, the IT grammar and the specifics of the phonology, morphology, syntax and semantics of the learner, a L2 or FL teacher may know the learner better, adopt a positive and practical attitude towards the learner's erroneous utterances and sentences, and adjust the teaching methods to the learner's needs. On the part of the L2 learner, realizing the nature of the IT grammar, he is likely to overcome his possible anxieties in L2 learning, have a strong and persistent motivation to elaborate his L2, and try to cultivate effective personal learning and communication strategies to approximate or internalize the TL better and faster.

\section{References}

Archibald, J. 1997. Second Language Acquisition. "Contemporary Linguistics", pp. 475-550, Boston, New York: Bedford/St. Martin's.

Corder, S.P. 1981. Error Analysis and Interlanguage. Oxford: Oxford University Press.

Dancygier, B. 1986. Languages Compared: Contrastive Analysis [In:] Introduction to Linguistics. 237-252. Warszawa: wydawnictwa Uniwersytetu Warszawskiego.

Kilborn, K. 1994. Learning a Language Late: Second Language Acquisition in Adults [In:] A. M. Gernsbacher (Ed.) Handbook of Psycholinguistics: San Diego, new York, Boston, London, Sydney, Tokyo, Toronto. Academic Press, pp. 917-944.

Lewandowska-Tomaszczyk, B. 1993. Second Language Acquisition in "Ways to Language - an Introduction to Linguistics", Łódź: Wydawnictwo Uniwersytetu Łódzkiego, pp. 235-248. 
Major, R. 1987. Foreign Accent: Recent Research and Theory in: "International Review of Applied Linguistics, 15, pp. 185-202.

Richards, J. 1978. Error Analysis and Second Language Learning Strategies in J. Schumann and N. Stenson (Eds.) New Frontiers in "Second Language Learning". Rowley. Mass.: Newbury House.

Schumann, J. 1978. Second Language acquisition: The Pidginization Hypothesis in E. Hatch, ed. 1978. "Second Language Acquisition: A Book of Reading". Rowley, Mass.: Newbury House.

Selinker, L. 1972. Interlanguage in "International Review of Applied Linguistics (IRAL)": Vol. 10.

Sobolew, L. 1986. Second Language Learning in "Introduction to Linguistics": 217-236. Warszawa: Wydawnictwo Uniwersytetu Warszawskiego. 